\title{
Patterns of exposure to infectious diseases and social contacts in early life and risk of brain tumours in children and adolescents: an International Case-Control Study (CEFALO)
}

TV Andersen*,1 , L S Schmidt ${ }^{1}$, A H Poulsen ${ }^{1}$, M Feychting ${ }^{2}$, M Röösli ${ }^{3,4}$, T Tynes $^{5,6}$, D Aydin ${ }^{3,4}$, M Prochazka ${ }^{2}$, B Lannering ${ }^{7}$, L Klæboe ${ }^{5,8}$, T Eggen ${ }^{5}$, C E Kuehni ${ }^{9}$, K Schmiegelow ${ }^{10,11}$ and J Schüz ${ }^{12}$

${ }^{1}$ Danish Cancer Society Research Center, Danish Cancer Society, Strandboulevarden 49, Copenhagen 2100, Denmark; ${ }^{2}$ Unit of Epidemiology, Institute of Environmental Medicine, Karolinska Institutet, Stockholm 171 77, Sweden; ${ }^{3}$ Department of Epidemiology and Public Health, Swiss Tropical and Public Health Institute, Basel 4051, Switzerland; ${ }^{4}$ University of Basel, Basel 4003, Switzerland; ${ }^{5}$ The Cancer Registry of Norway, Oslo 0304, Norway; ${ }^{6}$ National Institute of Occupational Health, Oslo 0033, Norway; ${ }^{7}$ Department of Pediatrics, The Queen Silvia Children's Hospital, University of Gothenburg, Gothenburg 416 85, Sweden; ${ }^{8}$ Norwegian Radiation Protection Authority, Oslo 1361, Norway; ${ }^{9}$ Swiss Childhood Cancer Registry, Institute of Social and Preventive Medicine, University of Bern, Bern 3012, Switzerland; ${ }^{10}$ Institute of Gynaecology, Obstetrics and Paediatrics, The Medical Faculty, University of Copenhagen, Copenhagen 2200, Denmark; ${ }^{11}$ Department of Paediatrics and Adolescent Medicine, Copenhagen University Hospital, Copenhagen 2100, Denmark and ${ }^{12}$ International Agency for Research on Cancer (IARC), Section of Environment and Radiation, Lyon 69372, France

Background: Infectious diseases and social contacts in early life have been proposed to modulate brain tumour risk during late childhood and adolescence.

Methods: CEFALO is an interview-based case-control study in Denmark, Norway, Sweden and Switzerland, including children and adolescents aged 7-19 years with primary intracranial brain tumours diagnosed between 2004 and 2008 and matched population controls.

Results: The study included 352 cases (participation rate: $83 \%$ ) and 646 controls (71\%). There was no association with various measures of social contacts: daycare attendance, number of childhours at daycare, attending baby groups, birth order or living with other children. Cases of glioma and embryonal tumours had more frequent sick days with infections in the first 6 years of life compared with controls. In 7-19 year olds with $4+$ monthly sick day, the respective odds ratios were 2.93 ( $95 \%$ confidence interval: 1.57-5.50) and 4.21 (95\% confidence interval: 1.24-14.30).

Interpretation: There was little support for the hypothesis that social contacts influence childhood and adolescent brain tumour risk. The association between reported sick days due to infections and risk of glioma and embryonal tumour may reflect involvement of immune functions, recall bias or inverse causality and deserve further attention.

Brain tumours are the second most frequent type of childhood cancer with a high mortality rate and a high frequency of longterm morbidity and psychosocial sequlae (Reimers et al, 2003). The annual incidence rates range from 20 to 40 cases per million children, with the highest rates reported in the Nordic countries (Peris-Bonet et al, 2006; Lannering et al, 2009; Schmidt et al, 2011).

*Correspondence: TV Andersen; E-mail: veje@cancer.dk

Received 11 December 2012; revised 26 March 2013; accepted 29 March 2013; published online 7 May 2013

(c) 2013 Cancer Research UK. All rights reserved 0007-0920/13 
Better knowledge of the aetiology of childhood and adolescent brain tumour (CABT) for primary prevention strategies is therefore important.

A review of epidemiologic studies by Schüz and Kaatsch, 2002 suggests that infections could initiate or modify the risk of CABT similar to the infection hypothesis that has been proposed for childhood acute lymphoblastic leukaemia (Schüz et al, 1999; Roman et al, 2007; Kamper-Jorgensen et al, 2008). Exposure to infectious agents early in childhood could cause an abnormal immune response when exposed to infectious diseases later in childhood (Kinlen, 1995; Greaves, 2006).

Some studies have not found an association between infectious agents and CABT (Birch et al, 1990; Little, 1999; McKinney et al, 1999). Most of these studies, however, had small sample sizes and therefore low statistical power to detect an association and other studies have found an association between risk of CABT and various measures of infectious diseases (Linet et al, 1996; Dickinson et al, 2002; Shaw et al, 2006) or indications of an association with exposure to polyoma viruses (SV40, JCV and BKV) (Bunin, 2000; Vilchez and Butel, 2003; Khalili et al, 2003).

Children's exposure to infectious diseases in early childhood is most commonly through contact with other children (Ma et al, 2009). Studies have shown that attending daycare increases a child's risk of getting infectious diseases (Thrane et al, 2001; KamperJorgensen et al, 2006; von Linstow et al, 2008), indicating that social contacts could reflect the general exposure to infections. Studies investigating the relationship between social contacts and CABT have, however, only found little or no evidence of an association (Shaw et al, 2006; Harding et al, 2009; Schmidt et al, 2010).

To evaluate the infection hypothesis for CABT further, we investigated the patterns of infectious diseases and social contacts in early life in relation to risk of developing a brain tumour during late childhood and adolescence in the CEFALO study.

\section{MATERIALS AND METHODS}

The CEFALO study is a multinational case-control study conducted in Denmark, Norway, Sweden and Switzerland, with the primary aim to investigate the possible association between CABT risk and mobile phone use and other relevant exposures (Aydin et al, 2011).

Case and control ascertainment. Eligible cases were children diagnosed with a primary intracranial brain tumour (Aydin et al, 2011) aged 7-19 years at the date of diagnosis. The study period was from 1 January 2004 until 1 August 2008, but varied slightly across the four countries (Denmark: January 2004-April 2008; Sweden: April 2004-August 2008; Switzerland: May 2004-2008; Norway: September 2004-August 2008).

To attain complete case ascertainment, cases were identified both at hospitals and in country-specific disease registries (the Danish National Cancer Registry (Tulinius et al, 1992; Storm et al, 1997); Danish Childhood Cancer Registry, Danish Pathology Registry, Danish National Patient Registry, the Swedish Regional Cancer Registries (Barlow et al, 2009), the Cancer Registry of Norway (Larsen et al, 2009) and Swiss Childhood Cancer Registry). Date of diagnosis was defined as date of first diagnostic imaging confirming a CABT.

Two controls per case were randomly selected from nationwide population registries in Scandinavia and in Switzerland from communal registries, and were individually matched by age (Denmark, Switzerland and Sweden: month of birth; Norway: year of birth), gender and region. Exposure of controls was censored at the date of diagnosis of the matched case.

Subjects diagnosed with Recklinghausen neurofibromatosis (12 cases) and tuberous sclerosis (one case) were excluded as their aetiology is genetic. Cases and controls with severe autism, severe mental retardation or complete deafness before the date of diagnosis were also excluded (two cases and two controls). In addition, families with insufficient language skills to complete an interview were excluded (15 cases and 36 controls). The study was approved by the National Data Protection Boards and ethical committees in all participating countries.

Data collection. Cases diagnosed before June 2006 (Norway: December 2007) and corresponding controls were included retrospectively. All other cases were included prospectively. A structured personal interview was performed with the child and one or preferably both parents by a trained interviewer during the time period 2006-2009. For ethical reasons, the interview was conducted at least 6 months after the date of diagnosis. Questionnaire translations were validated and pilot tested in all participating countries.

Variables and analysis strategy. We used the following variables as measures of social contacts and of exposure to infectious disease: living with other children before 6 years of age of index child (yes/ no); birth order (1st born/> 1st born); attending daycare in first year of life (yes/no) and before 6 years of age(yes/no); attending baby groups (at least once a week) within the first year of life (yes/ no); mean number of days where child's general condition was appreciably affected by infectious disease (once or less per month, 2-3 days per month, 4 days or more per month) at different ages $(<1,1-<3,3-<6$ years), calculated as a weighted average of answers provided per semester for the first 3 years of life and for the next 3 years of life combined (see Supplementary Appendix 1 online). The list of infectious diseases included: cold, fever without known cause, middle ear infection, tonsillitis, bronchitis, pneumonia, skin infection, urinary tract infection, stomach flu and others (e.g. whooping cough, 3-day fever, scarlet fever). For each child we also assessed cumulative daycare exposure by calculating total daycare childhours (categorised into quintiles) during the first 6 years of life as used by Ma et al (2002): Number of months attending a specific daycare $\times 4.35$ (average number of weeks per month) $\times$ hours per week at daycare $\times$ number of children at daycare. The childhours were cumulated over all daycare facilities attended during the time period of interest. As early brain tumourrelated symptoms might have influenced daycare attendance, all daycare information for the past 2 years before diagnosis or end of exposure date were disregarded (only relevant for the 7 and 8 year olds in our study). In addition, information on allergic conditions (yes/no) was available for all children, defined as having at any time before diagnosis of the matched case: doctors diagnosis of asthma, hay fever or eczema; or wheezing or whistling in the chest; itchy/watery eyes and sneezing/runny/blocked nose not in connection with a cold or the flu; or rash of folds of elbows, knees, front of ankles, under buttock or around neck, eyes or ears.

For statistical analysis, tumours were classified as: 'Glioma' (astrocytomas, other gliomas), 'intracranial embryonal CNS tumours' (including primitive neuroectodermal tumours (PNET)) and 'Others' (ependymoma, other specified intracranial neoplasms, unspecified intracranial neoplasms).

Data were analysed by conditional logistic regression in SAS (version 9.2; SAS Institute Inc., Cary, NC, USA). Relative risk estimates were expressed as odds ratios (OR) with associated 95\% confidence intervals (CI). Highest attained education of parents as a proxy for socioeconomic status was included in the models as potential confounder, but did not alter the risk estimates and was therefore omitted from the final model (data not shown).

\section{RESULTS}

In total, we invited 423 brain tumour cases and 909 controls and their families to participate in the CEFALO study. We interviewed 
352 cases and 646 controls with participation rates of 83 and $71 \%$, respectively. The most common reasons for non-participation are shown in Table 1.

The largest group of CABT in the study was glioma (55\%) followed by 'other tumours' (28\%) and intracranial embryonal tumours/PNET (18\%) (Table 1). This corresponds to the overall distribution of tumour types in the Nordic countries (Schmidt et al, 2011).

Overall there were slightly more boys than girls in the study. Two-thirds of the participating children and adolescents were between age 7 and 14 years, while only one third was between 15 and 19 years (Table 1). A large proportion of children attended daycare before 6 years of age $(87 \%)$. The majority of children attended baby groups (72\%) and most (94\%) of the index children were living together with siblings or other children. Regarding monthly number of days with infectious disease during the first 6 years of life, the majority of children were reported to have infectious disease once or less per month (67\%), 20\% 2-3 days per month and $9 \% 4$ days or more per month.

Overall, no OR of any measure of social contacts was statistically significantly increased or decreased (Table 2); this did not change when stratifying by gender (data not shown). Furthermore, no changes in ORs were observed when controlling for allergy (never/ ever allergy) (data not shown). However, a tendency of slightly increased risks were found for glioma and total childhours (only significant for fourth quintile; OR: 3.39; 95\% confidence interval (CI): 1.54-7.46), living with other children before 6 years of age (OR: 1.64 ; 95\% CI: $0.73-3.67$ ) and attending baby groups during the first year of life (OR: 1.47; 95\% CI: $0.95-2.28$ ). Such a pattern was not observed for other CABT.

With regard to infectious disease (Table 3), the OR for all CABT types combined was 1.27 (95\% CI: 0.89-1.80) for children having 2-3 sick days per month in the 0-6 years of age and 1.87 (95\% CI: 1.19-2.97) for children with 4 or more sick days per month (0-6 years) compared to children with one sick day or less per month (Table 3). Girls tended to have higher risk estimates for CABT than boys (data not shown). Controlling for diagnosed allergy did not alter the risk estimates. When stratifying by tumour type, increases were restricted to glioma and embryonal CNS tumours: an average of 4 or more monthly sick days at ages $0,0-2,3-5$ or $0-5$ years was associated with significantly increased risk of glioma. The observed risk was of similar magnitude, regardless of period of exposure, with the highest risk seen when looking at sick days over the first 6 years of life (OR: 2.93; 95\% CI: 1.57-5.50). There was a tendency for similar increases for embryonal CNS tumours, the risk estimates tended to be slightly lower than for glioma, except when looking at the first 6 years of life combined where the OR was 4.21 (95\% CI: 1.24-14.30), numbers were, however, small and the CI very wide.

For other CABTs, no indication of a risk increase with selfreported number of sick days was observed (Table 3).

We tested for interaction between total daycare childhours and number of days of infections $(0-<6$ years), as well as for birth order and number of days of infections $(0-<6$ years), but no interactions were found.

\section{DISCUSSION}

Overall, we found little evidence for an association between earlylife social contacts and CABT risk. There was no evidence of an exposure-response effect of higher CABT risk for cumulative childhours of attending daycare facilities. In all, confidence intervals for all social contact measures were relatively wide and no systematic patterns were observed. However, we found some evidence for an association between number of sick days due to

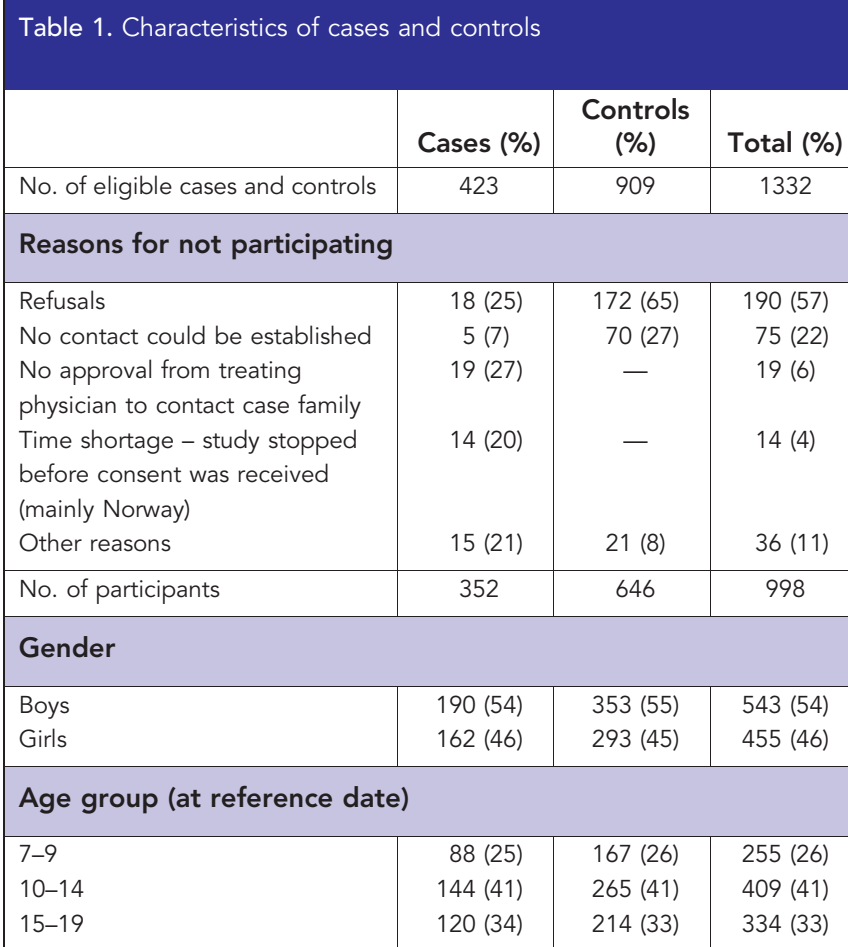

SES educational level of parents

\begin{tabular}{|l|c|c|c|}
\hline Basic & $20(6)$ & $26(4)$ & $46(5)$ \\
Medium & $188(53)$ & $336(52)$ & $524(53)$ \\
High & $144(41)$ & $279(43)$ & $423(42)$ \\
Not living with parents & - & $2(1 / 2)$ & - \\
Missing & - & $3(1 / 2)$ & - \\
\hline
\end{tabular}

Type of tumour (ICCC groups)

\begin{tabular}{|l|c|c|c|}
\hline Gliomas & $162(46)$ & - & \\
$\quad$ Astrocytomas (IIIb) & $30(9)$ & - & \\
$\quad$ Other gliomas (IIId) & $62(18)$ & - & \\
Intracranial embryonal CNS & & - & \\
tumours/PNET (IIIc) & $21(6)$ & - & \\
Other & $53(15)$ & - & \\
$\quad$ Ependymoma (IIla) & $24(7)$ & - & \\
Other specified intracranial & & \\
neoplasms (IIle) & & \\
Unspecified intracranial & & \\
neoplasms (IIIf) &
\end{tabular}

Abbreviations: $\mathrm{CNS}=$ central nervous system; $\mathrm{PNET}=$ primitive neuroectodermal tumour; ICCC $=$ International Classification of Childhood Cancer; SES = socioeconomic status.

infectious disease and CABT risk. When subdividing by tumour type, the effect was restricted to glioma and embryonal CNS tumours, with the results showing statistically significant positive associations for sick days at all ages.

Our findings of no increased CABT risk in relation to social contacts are broadly consistent with earlier studies, which showed only small or no associations (Shaw et al, 2006; Harding et al, 2009; Schmidt et al, 2010). The overall association of CABT with sick days because of infections found in this study is in agreement with some other studies; however, the majority of studies did not find an association (Little, 1999) and, in addition, no specific infectious agent had been identified (Schüz and Kaatsch, 2002).

The observed association between CABT and infections could result from a common underlying cause, for example, an immunological factor that increases both risk of tumour 


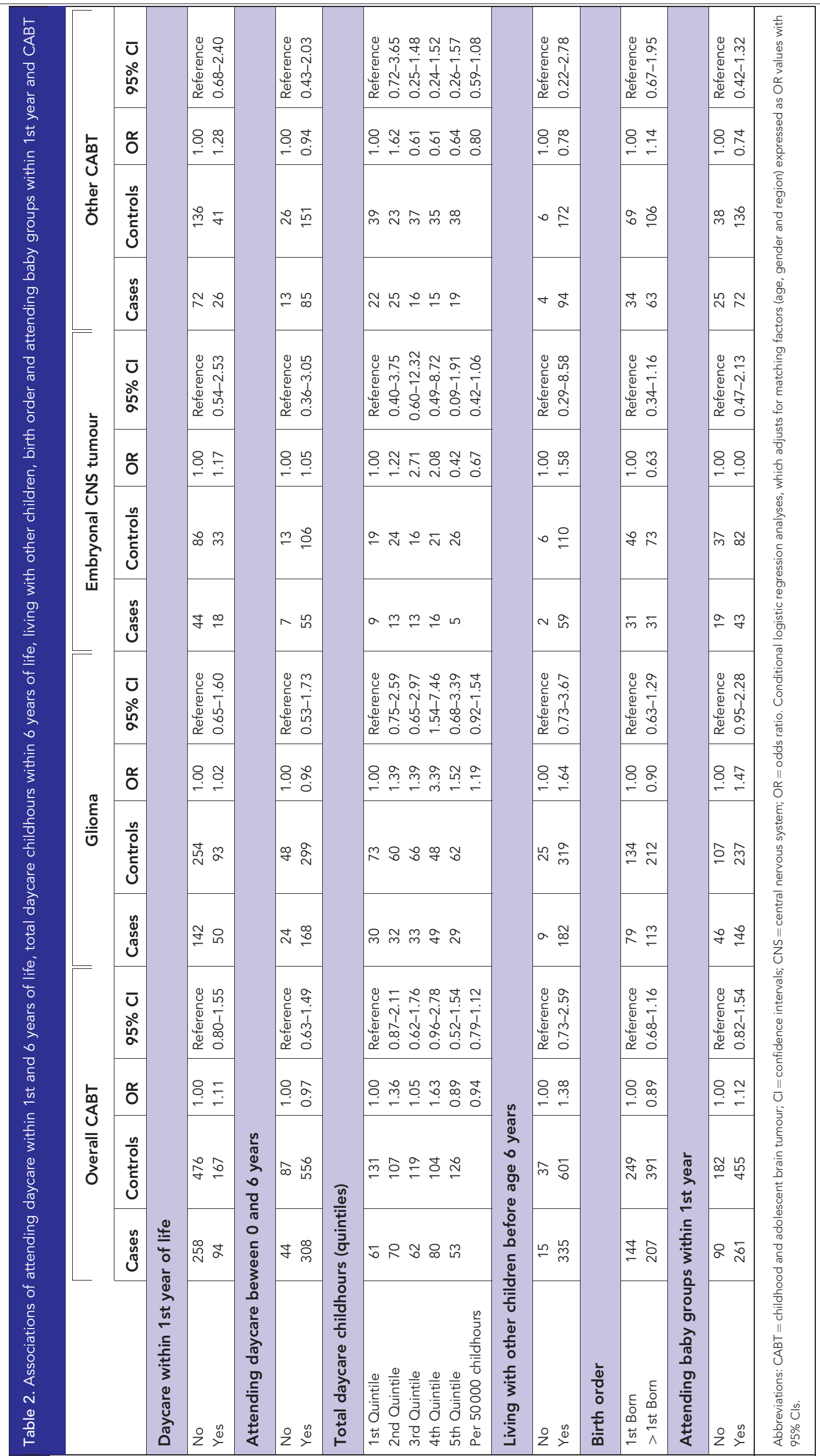


Table 3. Self reported sick days from infectious disease and risk of CABT

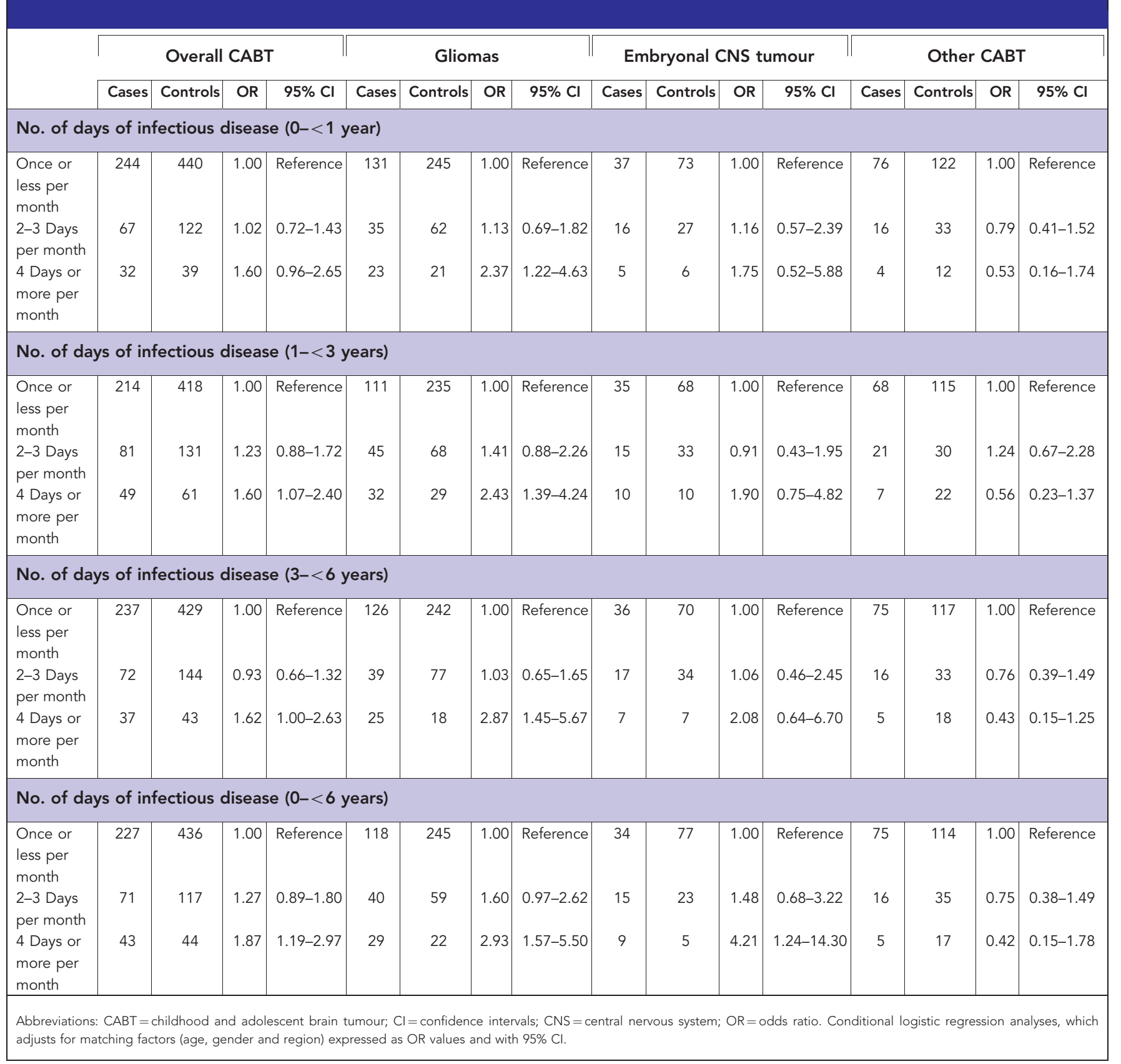

development and susceptibility to infectious disease. Also, we cannot rule out that inverse causality could be an explanation, as having a yet undiagnosed brain tumour could make the case children more susceptible to infections. Both of these explanations would fit with the fact that we observed no clear association with particular age periods when the infections occurred.

We estimated infections in the first 6 years of life from selfreport (infectious calendar developed for the purpose of this study, see Supplementary Appendix 1 online). Accurate recall of infectious episodes is, however, demanding (Schmidt et al, 2010) and laypersons may have difficulty in separating sick days due to infection from sick days for other reasons. Furthermore, case parents may have over-reported exposure, in an attempt to provide an explanation for the disease of their child; if so, one might expect them to do this for all age periods in the questionnaire, but inspection of the data for the most sick children showed no clear evidence of such an effect (data not shown). Alternatively, one could speculate that case parents might under-report sick days, as infections may be trivial compared with the later burden of having a child with a cancer diagnosis. In addition, common early symptoms of CABT include headache, nausea and vomiting (Wilne et al, 2007), and there may be a diagnostic delay of several years (ng-Tan and Franco, 2007, 2008; Wilne et al, 2007; Raab and Gartner, 2009) before the child is diagnosed with CABT; therefore, it is possible some reported infections of cases could reflect prodromal symptoms, even though we excluded any exposure occurring within 2 years of diagnosis. Altogether, the above factors may have introduced differential information bias. In this case we would, however, expect to find the same effect for all subtypes of CABT, whereas we only saw elevated risk estimates for glioma and embryonal CNS tumours, suggesting that biased reporting of infectious diseases is not a major concern. On the other hand, the group of other CABTs is small and the difference may be due to random variation. 
Another concern is if first born children may have had more sick days due to more concerned first time parents or due to better recollection of early life events (Sou et al, 2006). There was, however, no evidence of differential reporting of sick days for the first born children in our data as there was no statistically significant interaction between birth order and number of sick days.

Regarding social contacts, the above-mentioned diagnostic delay (Raaschou-Nielsen et al, 2006; ng-Tan and Franco, 2007, 2008; Wilne et al, 2007; Raab and Gartner, 2009) suggests confounding by indication as a potential concern as cases may have attended daycare less often compared with controls because of prodromal symptoms or other factors relating to a latent and undiagnosed CABT. This would lead to an underestimation of the association between social contacts and the risk of CABT.

Strengths of this study include the high participation rate, reducing the potential of selection bias, and the use of nationwide and high-quality registries (Tulinius et al, 1992; Storm et al, 1997; Barlow et al, 2009) in addition to case validation from treating physicians in hospitals ensuring a complete case ascertainment. Furthermore, cases were validated by unequivocal diagnostic imaging or histological confirmation ensuring correct diagnoses of included cases. The complete Scandinavian and Swiss population registers provided an optimal sampling frame for populationbased controls.

Daycare attendance before the age of 6 years was high in all countries (range: 63-97\%), making it a substantial source of social contacts with other children and therefore also for repeated contact with infectious agents. This in combination with a range of other measures of social contacts and infectious diseases allowed us to establish a quite detailed picture of the children's total exposure. This included also social contacts at home, where we could account for the complex modern family structure with cohabiting full, halfand step-siblings, whereas previous studies have not had any such information or at best had registered maternal birth order (Emerson et al, 1991; Linet et al, 1996; Heuch et al, 1998; Mogren et al, 2003; Von Behren and Reynolds, 2003; Altieri et al, 2006; Shaw et al, 2006; Schmidt et al, 2010).

With such a generally high proportion of children attending daycare, it became difficult to investigate daycare as a risk factor; however, we created the score of childhours at daycare as exposure gradient and did not observe an association with CABT risk when comparing children of the highest and lowest quintile of childhours at daycare. The distribution of attending daycare was skewed between the countries; we did, however, not have sufficient statistical power to perform country-specific analyses, but sensitivity analysis, removing one country at a time, did not substantially alter the results (data not shown).

Whereas interview information about birth order and living with other children is expected to be accurate, information on daycare attendance may be difficult to recollect many years later. We believe, in contrast to the reported infectious diseases, that it is unlikely that case and control parents remember daycare attendance differently. There is, however, the possibility that non-differential bias could influence the risk estimates, possibly leading to a dilution of the risk.

In conclusion, this study provides little evidence of an association between increased social contacts in early life, as measured by daycare attendance, participation in baby groups or living together with other children, and the risk of CABT in 7-19 year olds. However, we observed more frequent reported sick days because of infections in the first 6 years of life associated with the risk of glioma and possibly embryonal brain tumour. Although the association could result from chance or recall bias, it needs to be further studied to identify whether infectious disease early in life could represent early symptoms of CABT, have the same underlying cause as CABT or modulate the risk of developing a CABT.

\section{ACKNOWLEDGEMENTS}

The Danish part of the CEFALO study was supported by the Danish Strategic Research Council (Grant numbers 2103-05-0006 and 2064-04-0010). This particular part on social contacts and infections was funded by the Danish Childhood Cancer Foundation. The Swedish CEFALO study was supported by grants from the Swedish Council for Working Life and Social Research (Grant numbers 2004-0504 and 2007-0224), the Swedish Research Council (K2008-70X-15366-04-3), the Swedish Cancer Society (09 0666), the Swedish Childhood Cancer Foundation (Grant numbers PROJ06/050 and PROJ09/086) and the Swedish Radiation Protection Authority (SSI P 1572). The Swiss part of the CEFALO study was supported by the Swiss Federal Office of Public Health (Grant number 05.001626), the Swiss Research Foundation on Mobile Communication (Grant number A2006.18) and the Swiss National Science Foundation (Grant number PDFMP3 122873). The Norwegian CEFALO study was supported by the Research Council of Norway (Grant number 175163/V40).

Sweden: The Swedish collaborative group thanks the hospital staff, the Swedish Regional Cancer Registries and the Swedish Childhood CNS Tumour Group for their collaboration and valuable contributions to the CEFALO study. We thank the following key persons at the hospitals: Dr Johan Lundgren (Department of Pediatrics, University Hospital, University of Lund); Dr Ulf Samuelsson (Department of Pediatrics, University Hospital, Linkoping); Dr Stefan Holm (Department of Pediatrics, Astrid Lindgren Children's Hospital, Karolinska University Hospital, Stockholm); Dr Per Erik Sandström (Department of Pediatrics, University Hospital, Umeå); Dr Bo Strömberg (Department of Pediatrics, Akademiska Children's Hospital, Uppsala). The Swedish Childhood Cancer Registry was a valuable resource for the clinics. We gratefully acknowledge the research nurses Birgitta Ohlander and Annika Lilienberg for skilful work.

Switzerland: The Swiss collaborative group would like to thank Daniela Jenni, Diane Rey and Nicole Jakubowitz, who conducted interviews with participants. We would also thank the following persons from the hospitals and cancer registries for their valuable collaboration: Karin Zimmermann and Nadine Beusch (Department of Pediatric Haematology and Oncology, Inselspital Bern), Ursula Schönenberger (Secretariat Meurosurgery, Canton Hospital of Aarau), Verena Stahel (Department Haematology and Oncology, Children's Hospital Basel), Nicole Jakubowitz, Sandra Ettlin (Children's Hospital Lucerne), Maria Isabel Bartolome-Vegas (Secretariat, Cantons Hospital Lucerne), Nadja Blöchlinger (Secretariat, University Hospital Zürich), Dr Luisa Nobile (Department of Pediatrics, Canton Hospital Ticino), Franziska Hochreutener (Secretariat, Children's Hospital St Gallen), Heike Markievicz (Department of Oncology, Children's Hospital Zürich), Rosemarie Burri (Secretariat Neurosurgery, Insel Hospital Berne), Professor Dr Hans Landolt (Department Neurosurgery, Canton Hospital Aarau), Karl Kothbauer (Department Neurosurgery, Canton Hospital Lucerne), Regula Angst (Department Oncology, Canton Hospital Aarau), Professor Dr Michael Paulussen (Department Pediatric Oncology and Haematology, Children's Hospital Basel), Dr Heidi Baechli (Department Neurosurgery, University Hospital Basel), Professor Andreas Hirt (Department Pediatric Haematology/Oncology, Insel Hospital Bern), Anton Lukes (Department Pediatric Neurosurgery, University Hospital Bern), Ueli Caflisch (Children's Hospital Lucerne), Heinz Hengartner (Department Oncology and Haematology, Children's Hospital St Gallen), Bettina Gers (Department Neurosurgery, Canton Hospital St Gallen) and René Bernays (Department Neurosurgery, University Hospital Zürich).

Norway: The Norwegian collaborative group would like to thank Dr Med Finn Wesenberg (Pediatric Department, Rikshospitalet 
University Hospital, Oslo), who contributed to the planning of the project and verified the Norwegian case patients. We also thank some other key persons at the hospitals: Dr Rupavathana Mahesparan (Neurosurgical Department, Haukeland University Hospital, Bergen), Dr Mikael Donner (Pediatrics Department, Haukeland University Hospital, Bergen), Dr Randi Nygaard (Department of Pediatrics, St Olav University Hospital of Trondheim) and Dr Johan Cappelen (Department of Neurosurgery, St Olav University Hospital of Trondheim). We gratefully acknowledge research assistant Margareth Kaurin for her skilful work.

Denmark: The Danish collaborative group is thankful for all the help and cooperation from Danish hospitals. We would especially like to express our gratitude to the following: Staff specialist Astrid Sehested (Copenhagen University Hospital), Consultant neurosurgeon Lars Bøgeskov (Department of Neurosurgery, Copenhagen University Hospital), Consultant neurosurgeon Jannick Brennum (Department of Neurosurgery, Glostrup Hospital), Clinical associate professor Niels Carlsen (Department of Paediatrics, Odense University Hospital), Consultant neurosurgeon Morten Søe (Department of Neurosurgery, Odense University Hospital), Consultant paediatrician Steen Rosthøj (Department of Paediatrics, Aarhus University Hospital, Aalborg Hospital), Chief neurosurgeon Preben Sørensen (Department of Neurosurgery, Aarhus University Hospital, Aalborg Hospital), Consultant neurosurgeon Leif Christensen (Department of Neurosurgery, Aarhus University Hospital, Aarhus Hospital), Consultant paediatrician Niels Clausen (Department of Paediatrics, Aarhus University Hospital Skejby), Consultant paediatrician Henrik Schrøder (Department of Paediatrics, Aarhus University Hospital Skejby).

We thank Drs Jorgen $\mathrm{H}$ Olsen and Christoffer Johansen for their support in receiving the initial funding for the CEFALO study in Denmark. Furthermore, we would also like to thank Pernille Clausen, Henrik Gregersen, Martin Gregersen, Daniel Kristoffersen and Kenneth Widén at the Danish Cancer Institute for technical support. Also, a special thanks to Lissa Churchward and Gro Munk Nielsen at the Danish Cancer Society for supporting the administrative work.

\section{REFERENCES}

Altieri A, Castro F, Bermejo JL, Hemminki K (2006) Association between number of siblings and nervous system tumors suggests an infectious etiology. Neurology 67: 1979-1983.

Aydin D, Feychting M, Schüz J, Tynes T, Andersen TV, Schmidt LS, Poulsen AH, Johansen C, Prochazka M, Lannering B, Klaeboe L, Eggen T, Jenni D, Grotzer M, Von der WN, Kuehni CE, Roosli M (2011) Mobile phone use and brain tumors in children and adolescents: a multicenter case-control study. J Natl Cancer Inst 103(16): 1264-1276.

Barlow L, Westergren K, Holmberg L, Talback M (2009) The completeness of the Swedish Cancer Register: a sample survey for year 1998. Acta Oncol 48: 27-33.

Birch JM, Hartley AL, Teare MD, Blair V, McKinney PA, Mann JR, Stiller CA, Draper GJ, Johnston HE, Cartwright RA (1990) The inter-regional epidemiological study of childhood cancer (IRESCC): case-control study of children with central nervous system tumours. Br J Neurosurg 4: 17-25.

Bunin G (2000) What causes childhood brain tumors? Limited knowledge, many clues. Pediatr Neurosurg 32: 321-326.

Dickinson HO, Nyari TA, Parker L (2002) Childhood solid tumours in relation to infections in the community in Cumbria during pregnancy and around the time of birth. Br J Cancer 87: 746-750.

Emerson JC, Malone KE, Daling JR, Starzyk P (1991) Childhood brain tumor risk in relation to birth characteristics. J Clin Epidemiol 44: 1159-1166.

Greaves M (2006) Infection, immune responses and the aetiology of childhood leukaemia. Nat Rev Cancer 6: 193-203.

Harding NJ, Birch JM, Hepworth SJ, McKinney PA (2009) Infectious exposure in the first year of life and risk of central nervous system tumors in children: analysis of day care, social contact, and overcrowding. Cancer Causes Control 20: 129-136.
Heuch JM, Heuch I, Akslen LA, Kvale G (1998) Risk of primary childhood brain tumors related to birth characteristics: a Norwegian prospective study. Int J Cancer 77: 498-503.

Kamper-Jorgensen M, Wohlfahrt J, Simonsen J, Gronbaek M, Benn CS (2006) Population-based study of the impact of childcare attendance on hospitalizations for acute respiratory infections. Pediatrics 118: 1439-1446.

Kamper-Jorgensen M, Woodward A, Wohlfahrt J, Benn CS, Simonsen J, Hjalgrim H, Schmiegelow K (2008) Childcare in the first 2 years of life reduces the risk of childhood acute lymphoblastic leukemia. Leukemia 22: 189-193.

Khalili K, Del Valle L, Otte J, Weaver M, Gordon J (2003) Human neurotropic polyomavirus, JCV, and its role in carcinogenesis. Oncogene 22: $5181-5191$.

Kinlen LJ (1995) Epidemiological evidence for an infective basis in childhood leukaemia. Br J Cancer 71: 1-5.

Lannering B, Sandstrom PE, Holm S, Lundgren J, Pfeifer S, Samuelsson U, Stromberg B, Gustafsson G (2009) Classification, incidence and survival analyses of children with CNS tumours diagnosed in Sweden 1984-2005. Acta Paediatr 98: 1620-1627.

Larsen IK, Smastuen M, Johannesen TB, Langmark F, Parkin DM, Bray F, Moller B (2009) Data quality at the Cancer Registry of Norway: an overview of comparability, completeness, validity and timeliness. Eur J Cancer 45: 1218-1231.

Linet MS, Gridley G, Cnattingius S, Nicholson HS, Martinsson U, Glimelius B, Adami HO, Zack M (1996) Maternal and perinatal risk factors for childhood brain tumors (Sweden). Cancer Causes Control 7: 437-448.

Little J (1999) Epidemiology of Childhood Cancer. pp 235-236. IARC Press: Lyon, France.

Ma X, Buffler PA, Selvin S, Matthay KK, Wiencke JK, Wiemels JL, Reynolds P (2002) Daycare attendance and risk of childhood acute lymphoblastic leukaemia. Br J Cancer 86: 1419-1424.

Ma X, Urayama K, Chang J, Wiemels JL, Buffler PA (2009) Infection and pediatric acute lymphoblastic leukemia. Blood Cells Mol Dis 42: 117-120.

McKinney PA, Juszczak E, Findlay E, Smith K, Thomson CS (1999) Pre- and perinatal risk factors for childhood leukaemia and other malignancies: a Scottish case-control study. Br J Cancer 80: 1844-1851.

Mogren I, Malmer B, Tavelin B, Damber L (2003) Reproductive factors have low impact on the risk of different primary brain tumours in offspring. Neuroepidemiology 22: 249-254.

ng-Tan T, Franco EL (2007) Diagnosis delays in childhood cancer: a review. Cancer 110: 703-713.

ng-Tan T, Trottier H, Mery LS, Morrison HI, Barr RD, Greenberg ML, Franco EL (2008) Delays in diagnosis and treatment among children and adolescents with cancer in Canada. Pediatr Blood Cancer 51: 468-474.

Peris-Bonet R, Martinez-Garcia C, Lacour B, Petrovich S, Giner-Ripoll B, Navajas A, Steliarova-Foucher E (2006) Childhood central nervous system tumours - incidence and survival in Europe (1978-1997): report from Automated Childhood Cancer Information System project. Eur J Cancer 42: 2064-2080.

Raab CP, Gartner Jr. JC (2009) Diagnosis of childhood cancer. Prim Care 36 : 671-684.

Raaschou-Nielsen O, Sorensen M, Carstensen H, Jensen T, Bernhardtsen T, Gjerris F, Schmiegelow K (2006) Increasing incidence of childhood tumours of the central nervous system in Denmark, 1980-1996. Br J Cancer 95: 416-422.

Reimers TS, Ehrenfels S, Mortensen EL, Schmiegelow M, Sonderkaer S, Carstensen H, Schmiegelow K, Muller J (2003) Cognitive deficits in longterm survivors of childhood brain tumors: Identification of predictive factors. Med Pediatr Oncol 40: 26-34.

Roman E, Simpson J, Ansell P, Kinsey S, Mitchell CD, McKinney PA, Birch JM, Greaves M, Eden T (2007) Childhood acute lymphoblastic leukemia and infections in the first year of life: a report from the United Kingdom Childhood Cancer Study. Am J Epidemiol 165: 496-504.

Schmidt LS, Kamper-Jorgensen M, Schmiegelow K, Johansen C, Lahteenmaki P, Trager C, Stokland T, Grell K, Gustafson G, Kogner P, Sehested A, Schüz J (2010) Infectious exposure in the first years of life and risk of central nervous system tumours in children: analysis of birth order, childcare attendance and seasonality of birth. Br J Cancer 102: 1670-1675. Schmidt LS, Schmiegelow K, Lahteenmaki P, Trager C, Stokland T, Grell K, Gustafson G, Sehested A, Raashou-Nielsen O, Johansen C, Schüz J (2011) 
Incidence of childhood central nervous system tumors in the Nordic countries. Pediatr Blood Cancer 56: 65-69.

Schüz J, Kaatsch P (2002) Epidemiology of pediatric tumors of the central nervous system. Expert Rev Neurother 2: 469-479.

Schüz J, Kaletsch U, Meinert R, Kaatsch P, Michaelis J (1999) Association of childhood leukaemia with factors related to the immune system. $\mathrm{Br} J$ Cancer 80: 585-590.

Shaw AK, Li P, Infante-Rivard C (2006) Early infection and risk of childhood brain tumors (Canada). Cancer Causes Control 17: 1267-1274.

Sou SC, Chen WJ, Hsieh WS, Jeng SF (2006) Severe obstetric complications and birth characteristics in preterm or term delivery were accurately recalled by mothers. J Clin Epidemiol 59: 429-435.

Storm HH, Michelsen EV, Clemmensen IH, Pihl J (1997) The Danish Cancer Registry - history, content, quality and use. Dan Med Bull 44: 535-539.

Thrane N, Olesen C, Md JT, Sondergaard C, Schonheyder HC, Sorensen HT (2001) Influence of day care attendance on the use of systemic antibiotics in 0 - to 2-year-old children. Pediatrics 107: E76.
Tulinius H, Storm HH, Pukkala E, Andersen A, Ericsson J (1992) Cancer in the Nordic countries, 1981-86. A joint publication of the five Nordic Cancer Registries. APMIS Suppl 31: 1-194.

Vilchez RA, Butel JS (2003) SV40 in human brain cancers and non-Hodgkin's lymphoma. Oncogene 22: 5164-5172.

von Linstow ML, Holst KK, Larsen K, Koch A, Andersen PK, Hogh B (2008) Acute respiratory symptoms and general illness during the first year of life: a population-based birth cohort study. Pediatr Pulmonol 43: 584-593.

Von Behren J, Reynolds P (2003) Birth characteristics and brain cancers in young children. Int J Epidemiol 32: 248-256.

Wilne S, Collier J, Kennedy C, Koller K, Grundy R, Walker D (2007) Presentation of childhood CNS tumours: a systematic review and metaanalysis. Lancet Oncol 8: 685-695.

This work is published under the standard license to publish agreement. After 12 months the work will become freely available and the license terms will switch to a Creative Commons AttributionNonCommercial-Share Alike 3.0 Unported License.

Supplementary Information accompanies this paper on British Journal of Cancer website (http://www.nature.com/bjc) 